\title{
Hand Washing Practice and Associated Factors among Primary School Children in Damot Woide Woreda of Wolaita Zone, South Ethiopia: A Cross- sectional study
}

Amha Admasie ( $\nabla$ amhad2002@yahoo.com )

Bahir Dar University https://orcid.org/0000-0002-9826-1270

Alemu Guluma

Wolaita Zone Health Office

Ashenafi Debebe

Wolaita Sodo University

\section{Research}

Keywords: Hand washing, practice, primary school, school children, students, school-age children

Posted Date: November 19th, 2020

DOI: https://doi.org/10.21203/rs.3.rs-110596/v1

License: (c) (i) This work is licensed under a Creative Commons Attribution 4.0 International License.

Read Full License 


\section{Abstract}

Background: Diarrhea and respiratory infections are respectively the leading causes of childhood mortality globally. Hand washing at schools with soap could substantially reduce diarrhea and respiratory infections among school-age children, however in developing countries it is still being practiced to a very low extent in particular critical moments such as before eating and after using sanitation facilities including toilet. Therefore, the main aim of this study was to determine the level of hand washing practice and associated factors among primary school children in Damot Woide Woreda, Wolaita zone, South Ethiopia.

Methods: School based cross sectional study was conducted from January, 2018-February, 2018 using multistage cluster sampling technique and 580 students from six primary schools of grade 5-8 were included in the study and simple random sampling was employed to select study participants. Data was collected by using interviewer administered structured and pre-tested questionnaires by trained data collectors. Data entered in to Epi Data version 3.1 and exported into SPSSv20 for analysis. Both bivariate and multivariable logistic regression analyses were used.

Result: Twenty eight point one percent (28.10\% of [95\% Cl: $24.5-31.7])$ students had practiced proper hand washing. The multivariate model depicted that being grade $8^{\text {th }}$ [AOR $\left.=3.44,95 \% \mathrm{Cl}: 1.52,8.23\right]$, urban residence[AOR $=18.84,95 \% \mathrm{Cl}: 14.02,23.29]$, having parents [AOR $=10.74 ; 95 \% \mathrm{Cl} 8.80$ to 12.36 ], teachers as a role models $[\mathrm{AOR}=6.45 ; 95 \% \mathrm{Cl} 5.52$ to 8.99 ] and health professionals as a role models [AOR $=9.62$; $95 \% \mathrm{Cl} 2.70$ to 14.19$]$, and presence of hand washing facility in school [OR $=3.84,95 \% \mathrm{Cl}: 3.60,4.07]$ were found to be significantly associated with proper hand washing practice.

Conclusion: Proper hand washing practice among school children was found to be low. Therefore, promoting and enhancing hand washing practices and preparing hand-washing facilities in schools is mandatory to addressing the gap on hand washing practice among primary school students in the study area.

\section{Background}

Hand washing is defined as the vigorous, brief rubbing together of all surfaces of lathered hands, followed by rinsing under a stream of water, with a fundamental principle of removal, not killing of microorganisms. It has been globally acknowledged and accepted as a low cost and effective technique in preventing communicable diseases. It has been recognized as an important public health measure in preventing and controlling most infectious diseases(1). Hand washing is a basic, everyday process, and it is a skill and behavior that must be learned as a child and should become a lifelong habit in order to enjoy a better quality of life $(2,3)$.

School-aged children in developing countries do not usually engage in hand washing practice at critical time, such as after using the toilet, before eating and before cooking the food $(4,5)$. Proper hand washing practice is a prerequisite to a child's survival and responsible for the majority of child deaths globally 
each year $(3,6)$. Hand washing with soap could substantially reduce diarrhea and respiratory infections; never the less, in developing countries hand washing is still being practiced in less than five percent of the population especially at those critical moments (7).

In developing country, only $59 \%$ urban and $22 \%$ rural people have access to improved water and sanitation facilities $(2,8)$. Inadequate sanitary conditions and poor hygiene practices play major roles in the increased burden of communicable disease within these developing countries (9). Global burden of disease can be reduced by 9.1 percent and $6.3 \%$ of all global deaths can be halted through improving access to water, sanitation, and hygiene (WASH) $(10,11)$. WASH interventions have shown significant reductions in school absenteeism, and may have a positive influence on educational outcomes $(10,12)$. The use of sanitary facilities and hand washing practices as an important life skill for school children (13). In Colombia, $36.6 \%$ of school children reported to wash hands always with soap and very often after using the toilet, however, only $3 \%$ always washing hands for at least 20 seconds (14); in Bogota, only $33.6 \%$ always or very often washing hands with soap and clean water before eating and after using the toilet, while about $7 \%$ of students reported regular access to soap and clean water at school (15); in Bangladesh, washing hands specifically using soap after defecation was found to be a common practice(16); in Vietnam, the common time for hand washing was before eating $(60 \%)$, but only $23 \%$ after defecation and very few did before cooking (only $7 \%$ ), washed their hands at recommended duration (30$60 \mathrm{sec}$ ) was $58 \%$, the proportion of hand washing practice was increased by grade levels (34\% among grade 1 to $67 \%$ among grade 7 students(17); in South Africa, washing of hands in schools was above $65 \%(70.3 \%$ in urban and $29.7 \%$ in rural schools, they did mostly before eating and after visiting the toilet (18).

According to a Knowledge, Attitude and Practices (KAP) study in Angolela woreda, northern Ethiopia hand washing practice on the day before the interview was $99.7 \%$ ( $99 \%$ before meals, $46 \%$ after meals, and only $15 \%$ after defecation), majority of them practiced using plain water with only $36.2 \%$ of them used soap (19); in Babile town Eastern Ethiopia, 98.3\% of children regularly practiced hand washing before meals (20); in Arba Minch Town Southern Ethiopia, 79.1\% washed their hands with soap after visiting toilet and before meal, $22.3 \%$ of them properly applied hand washing practice (21).

Practice of hand washing in primary school children's interventions with soap have proven to be effective in reducing infectious diseases in school community. It is linked with the availability and accessibility of hand washing facilities (21-23). A school based study in Bogota, Colombia showed that being urban schools, availability of water and soap were three times more likely to wash their hands before eating and after visiting the toilet (24); another study in Vietnam and Peru reviled that being urban primary schools, far distance of hand washing facilities in schools, lack of water, lack of soap, and learning in a very crowded situation were the main reason for not washing their hands at school (25).

In Sierra Leon, primary school students had learned about hand washing from home (75\%), schools $(56 \%)$, radio or television $(36 \%)$, health facilities $(8 \%)$ and friends $(5 \%)$, students residing in urban areas are more likely to report home as a source of knowledge than those in rural areas; and students in rural 
areas are more likely to report school as a source of knowledge than those in urban areas $(22,26)$; in Indonesia the parents were the most frequent human source of information about hand washing $(91.86 \%)$, followed by health workers $(50.0 \%)$, teachers $(34.9 \%)$ and friends $(2.3 \%)$, the reasons for not washing hands were forgetfulness (81.8\%), laziness (13.2\%), lack of time (4.3\%), lack of interest $(0.8 \%)$, lack of clean water $7.8 \%$, and lack of soap $8.9 \%(27)$.

Education of household head and respondent, water availability and access to media have strong positive association with hand washing with soap (28), availability of water in some rural schools (18), availability of hand washing facilities in most schools, high pupil-to-hand washing facilities ratio, availability of soap, extensive use of shared containers, delays in acquisition of hand washing facilities, fragmented private sector efforts in hand hygiene promotion and non-compliance with conventional hand washing practices are factors affecting hand washing (28).

Despite substantial evidence about the effectiveness of hand washing, especially using soap at all critical time is proven globally and continentally, the level of practice of hand washing in Ethiopian schools is not well known. Therefore, the main aim of this study was to determine the level of hand washing practice and associated factors among primary school children in Damot Woide Woreda, Wolaita zone, South Ethiopia.

\section{Methods And Materials}

\section{Study setting and period}

The study was conducted in Damot Woide Woreda, Wolaita Zone, Ethiopia. Damot Woide Woreda is located around $400 \mathrm{~km}$ away from Addis Ababa the Capital of Ethiopia. It has a total population of 119,339, there are 31 primary schools (6 in urban and 25 in rural Kebeles) and two high schools(29). The Woreda has four health centers, 22 health posts, 12 private clinics and one private drug store. Intestinal parasitoid and diarrheal diseases are the $2 \mathrm{rd}$ and 3 th leading causes of outpatient diagnosis morbidity in the 10 top disease lists(30). The tudy was conducted from January-2018-February-2018.

\section{Study design and population}

School based cross-sectional quantitative study was employed on randomly selected school-age children (grade 5-8 students) from selected primary schools of Damot Woide Woreda, south Ethiopia.

\section{Inclusion and exclusion criteria}

All students grade 5-8 from selected primary schools who are registered and active student during the study period were included. However, those students with hearing, speaking, disabilities problems and students attending evening classes were excluded.

\section{Variables and Operational definition}


The dependent variable for the study was hand washing practice, while socio demographic factors and, institutional factors, personal factors and social factors (important referents, source of information, school wash club, mini-media and celebrating hand washing day) were predictor variables. To assess the level of hand washing practices, respondents were asked 7 questions and those who scored more than the mean value were considered as having good Practices (i.e. correctly responded to at least four out of seven practice questions) and those who scored less than the mean value were considered as having poor practices (correctly responded to less than four out of seven practice questions) $(31,32)$.

\section{Sample size and Sampling procedure}

Sample size was calculated by using single population proportion statistical formula with an assumptions of the proportion of improper hand washing practice $77.7 \%$ (21), a 95\% confidence level with a $5 \%$ margin of error and a design effect of 2 were considered; furthermore, $10 \%$ of the calculated sample size was added for possible non-response. In the multistage cluster random sampling technique initially, schools (Grade 5-8) were stratified in to urban and rural schools. Then, one urban school and five rural schools were selected purposively. Five hundred eight six students were selected from six schools proportionally. List of students were obtained from the school roaster list. Each participant student was selected by lottery method from the roaster list.

\section{Data collection tools, procedures and quality assurance}

Data was collected by interviewer-administered questionnaire with close-ended questions. The questionnaire was adopted from different published literatures(33), and WHO survey of school WASH program. The questionnaire was first prepared in English and translated in to Wolaitato (local language) and back to English to keep consistency of the questionnaires by involving language experts. Six trained health professionals (environmental health officers, public health nurses) has been involved in data collection with the supervision of two environmental health officers in a daily basis. Data collectors and supervisors were trained for two days on the whole process of data collection. Pre-test (on $5 \%$ of the total sample size) was conducted in Sake primary school, which has the same socio-demographic characteristics with that of the study schools. Based on the pretest, questions were revised, edited and the necessary corrections were made accordingly before the actual data collection is started.

\section{Data management and analysis}

Data was checked for completeness, edited manually, coded and then entered in to Epi Data version3.1 and exported into SPSS version 20 for clearance and analysis. Bivariate and multivariable logistic regression analysis was used. All factors with a p-value less than 0.25 in the bivariate logistic regression analysis were considered for multivariable analysis. Both crude and adjusted odds ratio with $95 \%$ confidence interval was reported. Multi-collinearity tests were conducted using variance inflation factor and tolerance. Hosmer and Lemeshew Goodness of fit test were used to check for model fitness. Variables with p-value less than 0.05 in multivariable analysis were considered as statistically significant. 


\section{Results}

\section{Socio-demographic characteristics}

From a total of 586 students, 580 students were successfully completed survey questions (response rate of $98.9 \%)$. The mean age of respondents was $13.29 \pm 1.66$ years, $174(30 \%)$ were grade six students and, $168(29 \%)$ were grade five. Majority $373(64.30 \%)$ were protestant religion followers, and $449(77.50 \%)$ were

living in rural area at the time of the survey. Concerning students' mothers educational and occupational status $130(20.40 \%)$ and 359(61.90\%) are non-educated and house wife respectively (Table 1). 
Table 1

Socio demographic characteristics of the students in Damot Woide Woreda primary schools, Wolaita zone, Ethiopia, May 2018. $(n=580)$

\begin{tabular}{|c|c|c|c|}
\hline Variable & Response & Frequency & Percent \\
\hline \multirow[t]{4}{*}{ Grade } & Grade 5 & 168 & $29.00 \%$ \\
\hline & Grade 6 & 174 & $30.00 \%$ \\
\hline & Grade 7 & 130 & $22.40 \%$ \\
\hline & Grade 8 & 108 & $18.60 \%$ \\
\hline \multirow[t]{2}{*}{ Age (year) } & $<14$ & 334 & $57.60 \%$ \\
\hline & $\geq 14$ & 246 & $42.40 \%$ \\
\hline \multirow[t]{2}{*}{ Sex } & Male & 268 & $46.20 \%$ \\
\hline & Female & 312 & $53.80 \%$ \\
\hline \multirow[t]{2}{*}{ Residence } & Urban & 131 & $22.50 \%$ \\
\hline & Rural & 449 & $77.50 \%$ \\
\hline \multirow[t]{4}{*}{ Maternal Education } & Illiterate & 174 & $30 \%$ \\
\hline & Grade 1-8 & 228 & $39.30 \%$ \\
\hline & Grade $9-12$ & 108 & $18.60 \%$ \\
\hline & Grade $\geq 12$ & 70 & $12.10 \%$ \\
\hline \multirow[t]{2}{*}{ Maternal occupation } & House wife & 359 & $61.90 \%$ \\
\hline & Non house wife* & 221 & $38.10 \%$ \\
\hline \multirow[t]{4}{*}{ Fathers education } & Illiterate & 130 & $22.40 \%$ \\
\hline & Grade $1-8$ & 174 & $30 \%$ \\
\hline & Grade $9-12$ & 178 & $30.70 \%$ \\
\hline & Grade $\geq 12$ & 98 & $16.90 \%$ \\
\hline \multirow[t]{2}{*}{ Fathers occupation } & Farmer & 384 & $66.20 \%$ \\
\hline & Non Farmer** & 87 & $15 \%$ \\
\hline
\end{tabular}

Practice Of Hand Washing: 
Among respondents, 184 (32.3\%) and 147 (25.8\%) wash their hands after and before meal respectively. Respondents who had washed their hands in the morning of interview day were 520 (89.7\%). Three hundred nine (53.3\%) students had used only plain water and followed by 149 (25.7\%) who used plain water and soap for washing their hands. Majority of the study participants $305(52.6 \%)$ responded that they do not know for how long to wash their hands at a time and $388(66.9 \%)$ reported that they wash their hands often with water and soap before meal followed by those washing very often using water and soap 76 (13.1\%). Out of 580 students, $372(64.1 \%)$ students reported that they often wash their hands with water and soap after using toilet whereas only $74(12.8 \%)$ of students wash their hands always after using toilet. Overall $163(28.1 \%)$ of participants had good practice of hand washing (Table 2). 
Table 2

Hand washing practice of the students in Damot Woide Woreda primary schools in Wolaita zone, Ethiopia, May 2018( $\mathbf{n}=\mathbf{5 8 0})$

\begin{tabular}{|c|c|c|c|}
\hline Variable & Responses & Frequency & Percent \\
\hline \multirow[t]{2}{*}{ Washed their hands in the last 12 hours } & Yes & 570 & $98.30 \%$ \\
\hline & No & 10 & $1.70 \%$ \\
\hline \multirow[t]{5}{*}{ Usual hand washing time } & Before meal & 147 & $25.80 \%$ \\
\hline & After meal & 184 & $32.30 \%$ \\
\hline & After work & 89 & $15.60 \%$ \\
\hline & After play & 108 & $18.90 \%$ \\
\hline & After toilet & 42 & $7.40 \%$ \\
\hline \multirow[t]{4}{*}{ Items using for hand washing } & Plain water only & 309 & $53.30 \%$ \\
\hline & $\begin{array}{l}\text { Plain water with } \\
\text { Soap }\end{array}$ & 149 & $25.70 \%$ \\
\hline & $\begin{array}{l}\text { Plain water with } \\
\text { Ash }\end{array}$ & 39 & $6.70 \%$ \\
\hline & Other & 23 & $4 \%$ \\
\hline \multirow[t]{3}{*}{ More practiced to wash hand in the family } & Ash and water & 28 & $4.80 \%$ \\
\hline & Soap and water & 203 & $35 \%$ \\
\hline & Water only & 349 & $60.20 \%$ \\
\hline \multirow[t]{3}{*}{ Duration of washing their hands at a time } & $<20 \mathrm{Sec}$ & 63 & $10.90 \%$ \\
\hline & $20 \mathrm{sec}-1 \mathrm{~min}$ & 212 & $36.60 \%$ \\
\hline & Do not know & 305 & $52.60 \%$ \\
\hline \multirow{4}{*}{$\begin{array}{l}\text { How often do you wash hands with soap before } \\
\text { meal? }\end{array}$} & Always & 50 & $8.60 \%$ \\
\hline & very often & 76 & $13.10 \%$ \\
\hline & Often & 388 & $66.90 \%$ \\
\hline & some times & 66 & $11.40 \%$ \\
\hline \multirow{4}{*}{$\begin{array}{l}\text { How often do you wash hands with soap after using } \\
\text { toilet? }\end{array}$} & Always & 74 & $12.80 \%$ \\
\hline & very often & 48 & $8.30 \%$ \\
\hline & Often & 372 & $64.10 \%$ \\
\hline & some times & 70 & $12.10 \%$ \\
\hline
\end{tabular}




\begin{tabular}{|llll|}
\hline Variable & Responses & Frequency & Percent \\
\hline Proper hand washing practice & Never & 16 & $2.80 \%$ \\
& Yes & 163 & $28.10 \%$ \\
\cline { 2 - 4 } & No & 417 & $71.90 \%$ \\
\hline
\end{tabular}

\section{Hand Washing Facilities In Students Home:}

Majority of the students $474(81.7 \%)$ reported as they have hand washing facility in the family and from which, 394(82.9\%) responded as it is functional. Two hundred thirty (39.7\%) students responded presence of only water for hand washing at home, while 396(68.3\%) reported the presence of water and soap for hand washing at home (Table 3).

Table 3

Hand washing facilities of the students' home in Damot Woide Woreda primary schools in Wolaita zone, Ethiopia, May 2018.

\begin{tabular}{|llll|}
\hline Variable & Response & Frequency & Percent \\
\hline Presence of hand washing facility in the home & Yes & 474 & $81.70 \%$ \\
\cline { 2 - 4 } & No & 106 & $18.30 \%$ \\
\hline Functional hand washing facility in the home & Yes & 394 & $82.90 \%$ \\
\cline { 2 - 4 } & No & 80 & $17.10 \%$ \\
\hline Time taken to fetch water in the home & $<15$ minutes & 360 & $62.10 \%$ \\
\hline Hand washing facilities in the home easy to Clean & Yes & 252 & $43.40 \%$ \\
\cline { 2 - 4 } & $>30$ min & 70 & $13 \%$ \\
\hline Presence of soap and water for hand washing at homes & Yes & 328 & $56.60 \%$ \\
\cline { 2 - 4 } & No & 154 & $68.30 \%$ \\
\cline { 2 - 4 } & & & $31.70 \%$ \\
\hline
\end{tabular}

\section{Personal And Social Factors For Hand Washing Practice:}

Majority of students 398(73.3\%) mentioned the benefit of hand washing in disease prevention. Three hundred twenty (55.2\%) respondents reported forgetfulness as the reason for not washing hands followed by laziness $78(13.4 \%)$. Majority of participants $509(87.8 \%)$ responded that as they know that poor hand washing causes disease. Two hundred sixty, (44.8) of respondents reported as plain water is 
enough for hand washing. Two hundred ninety-seven (51.2\%) participants reported that they need to wash their hands with soap if only they look filthy or smell bad. Majority of participants $175(30.2 \%)$ and $170(30 \%)$ reported as they had heard about hand washing from mini media and radio respectively. Referents of students for hand washing, $306(52.8 \%)$ and 124 (21.4\%) were parents and teachers respectively (Table 4).

Table 4

personal factors for children's hand washing practice in Damot Woide Woreda primary schools in Wolaita zone, SNNPR, Ethiopia, May 2018.

\begin{tabular}{|c|c|c|c|}
\hline Variable & Responses & Frequency & Percent \\
\hline \multirow[t]{4}{*}{ Benefit of hand washing } & To prevent disease & 398 & $73.30 \%$ \\
\hline & To free from bad smell & 48 & $8.80 \%$ \\
\hline & To remove dirt's & 42 & $7.70 \%$ \\
\hline & To clean hand & 49 & $9 \%$ \\
\hline \multirow[t]{6}{*}{ What are your reasons for not washing hands } & Forget fullness & 320 & 55.2 \\
\hline & Laziness & 78 & 13.4 \\
\hline & Lack of time & 36 & 6.2 \\
\hline & Lack of interest & 58 & 10.0 \\
\hline & Lack of water & 55 & 9.5 \\
\hline & Lack of soap & 33 & 6.0 \\
\hline \multirow[t]{6}{*}{ Source of media information about hand washing } & Television & 65 & 11.2 \\
\hline & Radio & 174 & 30.0 \\
\hline & Leaflets & 61 & 10.5 \\
\hline & News paper & 11 & 1.9 \\
\hline & Min-media & 175 & 30.2 \\
\hline & Text books & 94 & 16.2 \\
\hline \multirow[t]{4}{*}{ Referents (role model) for hand washing practice } & Parents & 306 & 52.8 \\
\hline & Teachers & 124 & 21.4 \\
\hline & Health professionals & 50 & 8.6 \\
\hline & Friends & 100 & 17.2 \\
\hline
\end{tabular}


Based on the observational check list, four out of six schools had handwashing facilities in their compound at a distance of less than 10 meters from the latrine facilities. But water access to handwashing facilities is only to three schools. There is no soap for handwashing facilities in all schools. The handwashing facilities in all schools are not connected to the pipe line, since the school had not water access though via pipe. In five schools, there are sanitation and hygiene clubs to provide awareness to school community, but only 4 schools clubs had broadcast hand washing promotion through mini-media. About five of the schools, celebrate annual Hand Washing Day.

Factors affecting hand washing practice in primary school children: On the result of multivariable logistic regression models, being grade 8th, living in urban area, having referents as parents, teachers and health professionals and presence of hand washing facility in the school were significantly associated to hand washing practice. Grade 8 students were 3.54 times more likely to practice proper hand washing practice compared to grade 5 students $(A O R=3.44,95 \% \mathrm{Cl}: 1.52,8.23)$. Students residing in urban area 18.84 times more likely to practice proper hand washing practice compared to students residing in rural area $(A O R=18.84,95 \% \mathrm{Cl}: 14.02,23.29)$.Students whose referents were parents, teachers, and health professionals were more likely $(\mathrm{AOR}=10.74 ; 95 \% \mathrm{Cl} 8.80-12.36, \mathrm{AOR}=6.45 ; 95 \% \mathrm{Cl} 5.52-8.99, \mathrm{AOR}=9.62$; $95 \% \mathrm{Cl} 2.70-14.19$ respectively) to practice proper hand washing practice compared to those whose referents were friends. Students attending in school where there is hand washing facility were 3.84 times more likely to practice proper hand washing practice compared to those who are learning in school where there is no hand washing facility (AOR $=3.84,95 \% \mathrm{Cl}: 3.60,4.07)$ (Table 5). 
Table 5

Predictor variable analysis of children's hand washing practice in Damot Woide Woreda primary schools in Wolaita zone, Ethiopia, May 2018.

\begin{tabular}{|c|c|c|c|c|c|}
\hline \multirow[t]{2}{*}{ Variable } & \multirow[t]{2}{*}{ Response } & \multicolumn{2}{|c|}{$\begin{array}{l}\text { Hand washing } \\
\text { practice }\end{array}$} & \multicolumn{2}{|l|}{ OR 95\% Cl } \\
\hline & & Proper & Improper & COR & AOR \\
\hline \multirow[t]{4}{*}{ Grade of students } & Grade 5 & 42 & 126 & 1.00 & \\
\hline & Grade 6 & 37 & 137 & $0.80(0.50,1.34)$ & $0.87(0.45,1.69)$ \\
\hline & Grade 7 & 45 & 85 & $1.58(0.96,2.60)$ & $1.54(0.75,3.16)$ \\
\hline & Grade 8 & 39 & 69 & $1.70(1.00,2.80)$ & $3.54(1.52,8.23)$ \\
\hline \multirow[t]{2}{*}{ Age } & $<14$ year & 103 & 231 & 1.00 & 1.00 \\
\hline & $\geq 14$ year & 60 & 186 & $0.72(0.49,1.05)$ & $0.38(0.21,1.70)$ \\
\hline \multirow[t]{2}{*}{ Sex } & Male & 84 & 184 & $1.34(0.94,1.93)$ & $1.15(0.70,1.90)$ \\
\hline & Female & 79 & 233 & 1.00 & 1.00 \\
\hline \multirow[t]{2}{*}{ Residence } & Urban & 72 & 59 & $4.70(3.17,7.26)$ & $18.84(14.02,23.29)$ \\
\hline & Rural & 91 & 358 & 1.00 & 1.00 \\
\hline \multirow[t]{4}{*}{ Maternal Education } & $\begin{array}{l}\text { Non- } \\
\text { educated }\end{array}$ & 27 & 147 & 1.00 & 1.00 \\
\hline & Grade 1-8 & 69 & 159 & $2.36(1.40,3.88)$ & $1.57(0.78,3.14)$ \\
\hline & Grade $9-12$ & 38 & 70 & $2.95(1.67,5.20)$ & $1.86(0.83,4.17)$ \\
\hline & $\begin{array}{l}\text { Grade }>= \\
12\end{array}$ & 29 & 41 & $3.80(2.05,7.20)$ & $2.79(0.89,8.70)$ \\
\hline \multirow[t]{4}{*}{ Paternal education } & $\begin{array}{l}\text { Non- } \\
\text { educated }\end{array}$ & 21 & 109 & 1.00 & 1.00 \\
\hline & Grade 1-8 & 47 & 127 & $1.92(1.08,3.41)$ & $1.16(0.54,2.48)$ \\
\hline & Grade $9-12$ & 56 & 122 & $2.38(1.38,4.18)$ & $1.56(0.72,3.36)$ \\
\hline & $\begin{array}{l}\text { Grade }>= \\
12\end{array}$ & 39 & 59 & $3.43(1.85,6.36)$ & $1.25(0.45,3.51)$ \\
\hline \multirow{4}{*}{$\begin{array}{l}\text { Referents for hand } \\
\text { washing practice }\end{array}$} & Parents & 99 & 207 & $7.50(3.17,17.69)$ & $10.74(8.80,12.36)$ \\
\hline & Teachers & 47 & 77 & $9.50(3.80,23.50)$ & $6.45(5.52,8.99)$ \\
\hline & $\begin{array}{l}\text { Health } \\
\text { personnel }\end{array}$ & 11 & 39 & $4.40(1.50,12.70)$ & $9.62(2.70,14.19)$ \\
\hline & Friends & 6 & 94 & 1.00 & 1.00 \\
\hline Hand washing & Yes & 158 & $\begin{array}{l}257 \\
\text { e } 13 / 18\end{array}$ & $3.44(2.15,5.50)$ & $3.84(3.60,4.07)$ \\
\hline
\end{tabular}




\section{Discussion}

The study revealed that proportion of student's hand washing practice in Damot Woide Woreda primary schools of Wolaita zone, Ethiopia was $28.10 \%(95 \% \mathrm{Cl}, 24.5,31.7 \%)$. Slightly higher proportion of students' hand washing practice was reviled as compared to the study conducted in Arba Minch town, Ethiopia which is (22.3\%) (21) and slightly lower proportion than a study conducted in Sebeta, Ethiopia (32\%) (34) where as a study in Colombia, showed $36.6 \%$ (14). The variability in proportion may be due to the difference in access of hand washing facility in school and households and, socio-demographic, educational, economic and cultural differences with the current study area.

This study identified associated factors of proper hand washing practice among students, grade 8 students were 3.54 times more likely to practice proper hand washing as compared to grade 5 students, this might be due to teachers focusing on higher grade students, and they could learn as their age is increasing and are more likely to practice what they learned. This study is comparable with in Vietnam in that the proportion of hand washing was increased by increasing students' grade level (17).

Students living in urban area were 18.84 times more likely to practice proper hand washing compared to students residing in rural area. Similar study was conducted in Arba Minch (21) and Bangladesh (28) revealed that urban students living in urban setting were more likely to practice proper hand washing than those living in rural area. This is may be due to behavioral differences among rural and urban dwellers and also due to inadequate access of water, hand washing facility and household level issues.

Students having important referents/role model to wash their hands as parents; teachers and health professionals were significantly associated factors of hand washing practice. Students whose referents were parents were 10.74 times, teachers were 6.45 times and health professionals were 9.62 times more likely to practice proper hand washing practice compared to those students whose important referents/role model to wash their hands were friends. This is in line with a study conducted in Indonesia and Arba Minch $(21,28)$. This might be due to close follow up of health extension worker, parents and teachers to the students. The pressure from peers/friends could be undermined than teachers and parents.

Students attending in school where there is a hand washing facility were 3.84 times more likely to practice proper hand washing than those who were attending in school where there is no hand washing facility. According to study conducted in Ghana, accessibility and availability of hand washing facilities in school (23) and in Indonesia, availability of clean water and soap at hand washing stands $(22,35)$ were found to be significant predictors of proper hand washing practice. This may be due to the fact that presence of hand washing facilities motivate the students to wash hand properly. This study was 
conducted in both urban and rural schools and data was collected by professionals who were involved in the similar studies before and can be considered as strength. Being cross sectional study design and majority of the finding is based on self- reported response of study participants however is a limitation of the current study.

\section{Conclusion}

The proportion of students who practiced proper hand washing in the school was low. Grade 8 students; urban students; students whose important referents for hand washing were parents, teachers and health professionals; and students who had access for hand washing facilities in schools were significant factors for proper practice of hand washing. Therefore, all primary schools should advocate and engage students on hand washing practice activities at the school and outside school. Rural health extension program should focus on hand washing practice in the family level and schools. Local government and nongovernment offices working in the area should support school clubs to teach/demonstrate proper hand washing practice by providing well-designed and well-located hand washing facilities. Finally, it is strongly recommended more robust research design for further studies, involving parents and more in observational and qualitative study design.

Ethical consideration: The ethical clearance was obtained from Ethical Review Committee of the College of Health Sciences, Wolaita Sodo University. After the approval, official letter of cooperation was written to Damot Woide Woreda education office. Permission letter was obtained from Woreda education office prior to data collection. The nature of the study was fully explained to the study participants and informed written consent was obtained from each school directors before data collection to maintain privacy and confidentiality. The participants were told that documents will be kept in secured place to not access to others and they have been informed that they have the right to refuse and withdraw the interview any time if they are not comfortable.

\section{Declarations}

Consent for publication: Not applicable

Availability of data and materials: The datasets used and/or analyzed during the current study are available from the corresponding author on reasonable request.

Competing interest: We declare that we have no any conflicts and any financial competing interests.

Funding: No funding was applicable.

Authors' Contributions: AG carried out protocol development, data collection, data management and analyses. AA was involved in protocol development, providing field work monitoring. AA and AD writing the manuscript. All authors read and approved the manuscript. 
Acknowledgements: We would like to gratefully acknowledge Wolaita zone health department, for the support and encouragement. Our thanks go to participant school communities, teachers and students, study participants, data collectors and supervisors for their time.

\section{References}

1. A De Francisco, J Morris, AJ Hall, JRM Armstrong Schellenberg, BM Greenwood. Risk Factors for Mortality from Acute Lower Respiratory Tract Infections in Young Gambian Children. International Journal of Epidemiology. 1993;22(6).

2. Adams PF, MA M. Lether up for good health. Class room guide. 2010.

3. Abhay B Mane, Nandika S Reddy, Partha Reddy, Chetana KV, Srijith S Nair, Sriniwas T. Differences of Hand Hygiene and its Correlates among School going Children in Rural and Urban Area of Karnataka, India. Archives of Medicine. 2016;8(5).

4. Rufus Eshuchi. Promoting handwashing with soap behaviour in Kenyan schools: Learning from puppetry trials among primary school children in Kenya: Queensland University of Technology; 2013.

5. Dhiraj Biswas, Sanjaykr Sahoo, Aparajita Dasgupta, PS Preeti, Amitavakumar, Sudipta Das. Quantification of Perception Status of Hand Washing Practice Among School Children In A Rural Area of West Bengal. Applide medical science. 2015;3(4):1683-7.

6. Rubanprem Kumar S.A, Aruna S, Sasikala M. Effectiveness of hand hygiene teaching on knowledge and compliance of hand washing among the students at a selected school in Mugalivakkam village, Kancheepuram District. IOSR-JNHS. 2014;3(4):56-60.

7. Yallew WW, Terefe MW, Herchline TE, Sharma HR, Bitew BD, Kifle MW, et al. Assessment of water, sanitation, and hygiene practice and associated factors among people living with HIV/AIDS home based care services in Gondar city, Ethiopia. BMC public health. 2012;12(1):1057.

8. Victoria Chioma Azuogu, Cajetan Ikechukwu Ilo, Ignatius Obilor Nwimo, Benedict Ndubueze Azuogu, Chinagorom Onwunaka. Extent Of Hand Washing Practice Among Secondary School Students In Ebonyi State, Nigeria. International Journal of Education, Learning and Development. 2016;4(7):1122.

9. M. Steiner-Asiedu, M. Papoe, J. Setorglo, S.E. Van-Ess, D.K. Asiedu. Hand Washing Practices among School Children in Ghana. Social science. 2011;3(4):393-00.

10. Adam Biran, Wolf-Peter Schmidt, Kiruba Sankar Varadharajan, Divya Rajaraman, Raja Kumar, Katie Greenland, et al. Effect of a behaviour-change intervention on handwashing with soap in India (SuperAmma): a cluster-randomised trial. Lancet global health. 2014;2(3):e145-54.

11. Ministry of Education. National School Water, Sanitation and Hygiene (SWASH) Implementation Guideline. Addis Ababa, Ethiopia: FDRE Ministry of Education; 2017. p. 45.

12. Cindy White, Robin Kolble, Rebecca Carlson, Natasha Lipson, Mike Dolar, Yusuf Ali, et al. The Effect of Hand Hygiene on IIIness Rate Among Students in University Residence Halls. Am J Infect Control. 2013;31(6):364-70. 
13. FMOH. School WASH Manual. 2005.

14. Rita Moses Mbeba. Factors that infulencing hand wash practice at primary school. Health and alian science. 2012; 27(6):1055-68.

15. Catalina Lopez-Quintero, Paul Freeman, Yehuda Neumark. Hand Washing Among School Children in Bogota', Colombia. Am j public health. 2009;99(1):94-101.

16. Tahera Akter, ARM Mehrab Ali. Factors influencing knowledge and practice of hygiene in Water, Sanitation and Hygiene programme areas of Bangladesh. Rural Remote Health. 2014;14(3):1-10.

17. Thi L, Xuan T, Hoat LN. Handwashing among schoolchildren in an ethnically diverse population in northern rural Vietnam. Global health action. 2013;1(2):1-8.

18. Sibiya JE, Gumbo JR. Knowledge, Attitude and Practices ( KAP ) Survey on Water , Sanitation and Hygiene in Selected Schools in Vhembe District, Limpopo, South Africa. International Journal of Environmental Research and Public Health. 2013;10(6):2282-95.

19. Vivas A, Gelaye B, Aboset N, Kumie A, Berhane Y, Williams MA. Knowledge, attitudes and practices (KAP) of hygiene among school children in Angolela, Ethiopia. J Prev Med Hyg. 2010;51(2):73-9.

20. Girum Tadesse. The prevalence of intestinal helminthic infections and associated risk factors among school children in Babile town, eastern Ethiopia. Ethiopian Journal of Health Development. 2005;19(2):140-7.

21. Behailu Besha, Hailu Guche, Dawit Chare, Abebech Amare, Amelmal Kassahun, Engida Kebede, et al. Assessment of Hand Washing Practice and its Associated Factors among First Cycle Primary School Children in Arba Minch Town, Ethiopia, 2015. Epidemiology (Sunnyvale). 2016;6(247):2161-1165.

22. Setyautami T, Sermsri S, Chompikul J. Proper hand washing practices among elementary school students in Selat sub-district, Indonesia. Journal of Public Health and Development 2012;10(2).

23. Monney I, Martinson OS, Asampana AM, Albert M. Assessing hand hygiene practices in schools benefiting from the Ghana School Feeding Programme. Science Journal of Public Health. 2014;2(1):7-14.

24. Lopez-Quintero, Catalina Freeman, Paul Freeman Neumark. Hand Washing Among School Children in Bogotá, Colombia. American Journal of Public Health. 2009;99(1):94-101.

25. Dutton P, Nguyen NK, Peschiera RF. The power of primary schools to change and sustain handwashing with soap among children : the cases of Vietnam and Peru (English). Washington, DC: World Bank, 2011 2011/09/01 00:00:00. Report No.: Contract No.: 66001.

26. UNICEF. WASH_for School Children South Asia_Report. 2012.

27. Tre setyautami, Santhat sermsri, Siraporn chompikul. Proper hand washing practices among elementary school students in selta sub-district,indonesia. Public health and development. 2012;10(2).

28. Rabbi SE, Dey NC. Exploring the gap between hand washing knowledge and practices in Bangladesh: a cross-sectional comparative study. BMC Public Health. 2013;13(89):1-7. 
29. Education office. Damot Woyde Woreda education office mid term report. [Mid term report]. In press 2010.

30. Health Office. Damot Woide Woreda Health Office anual report. In: Office DWWH, editor.: Damot Woide Woreda Health Office, Wolaita Zone, Ethiopia; 2009.

31. Zahra Cherraghi, Batul Okhovat, Amin Doosti, Mojgan Talaei, Elham Ahmadnezhad, Mohammad Mehadi Gooya, et al. Knowledge, Attitude, and Practice regarding Food, and Waterborne Outbreak after Massive Diarrhoea Outbreak in Yazd Province, Iran, Summer 2013. International Scholarly Research Notices. 2013;2014(403058.):7.

32. Asekun-Olarinmoye Esther. Hand Washing: Knowledge, Attitude and Practice amongst Mothers of Under-Five Children in Osogbo, Osun State, Nigeria. Journal of Biology, Agriculture and Healthcare 2014;4(16).

33. Central Statistical Agency. Ethiopia Demographic and Health Survey 2016. Addis Ababa, Ethiopia, and Rockville, Maryland, USA: CSA and ICF: 2016.

34. Mulubirhan Assefa, Abera Kumie. Assessment of factors influencing hygiene behaviour among school children in Mereb-Leke District, Northern Ethiopia: a cross-sectional study. BMC public Health. 2014;14(1000):1471-2458.

35. Ramos MM, Blea M, Trujillo R, Greenberg C. Inspections of hand washing supplies and hand sanitizer in public schools. J Sch Nurs 2010;26(5):393-7.

\section{Figures}

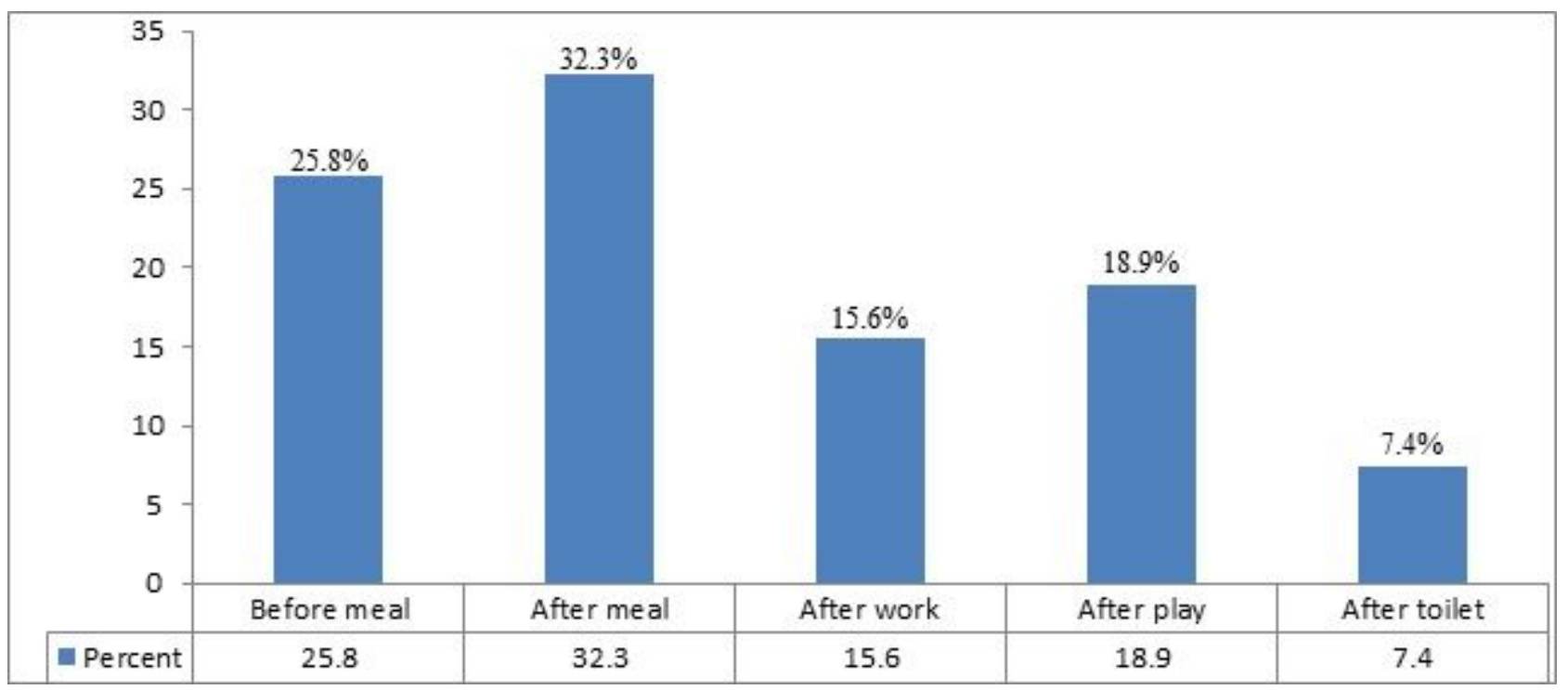

\section{Figure 1}

Usual hand washing time of students in Damot Woide Woreda primary schools in Wolaita zone, Ethiopia, May 2018. 